\title{
COOLING WATER SYSTEMS DESIGN USING PROCESS INTEGRATION
}

\author{
Khunedi Vincent Gololo ${ }^{1,2}$ and Thokozani Majozi ${ }^{1 *}$ \\ ${ }^{1}$ Department of Chemical Engineering, University of Pretoria, Lynnwood Road, Pretoria, 0002, South Africa \\ ${ }^{2}$ Modelling and Digital Science, Council for Scientific and Industrial Research (CSIR), Pretoria, South Africa \\ *E-mail: thoko.majozi@up.ac.za
}

\begin{abstract}
Cooling water systems are generally designed with a set of heat exchangers arranged in parallel. This arrangement results in higher cooling water flowrate and low cooling water return temperature thus reducing cooling tower efficiency. Previous research on cooling water systems has focused mainly on heat exchanger network thus excluding the interaction between heat exchanger network and the cooling towers. This manuscript presents a technique for grassroot design of cooling water system for wastewater minimization which incorporates the performances of the cooling towers involved. The study focuses mainly on cooling systems consisting of multiple cooling towers that supply a common set of heat exchangers. The heat exchanger network is synthesized using the mathematical optimization technique. This technique is based on superstructure in which all opportunities for cooling water reuse are explored. The cooling tower model is used to predict the thermal performance of the cooling towers.
\end{abstract}

\section{KEY WORDS}

Mathematical optimization; Cooling water system; Cooling tower; Heat exchanger network

\section{Introduction}

Industrial development and other economic activities have led to an increase in fresh water consumption and contamination of freshwater resources. One of the major water using operations in industries is the cooling water systems. Cooling water systems use equipments such as cooling towers to remove waste heat from the process to the atmosphere. These systems also generate wastewater through the blowdown mechanisms. Escalating costs of waste treatment, stricter environmental regulations on industrial effluent and scarce water resources have led to studies which concern various means of minimizing water usage and waste generation.
Previous research on cooling water systems has focused mainly on minimizing water usage by optimizing heat exchanger networks. The common tool used in this regard was pinch analysis developed by Linnhoff and co workers in the early 80's. This technique was adopted for mass exchanger network design [1] and later developed into WaterPinch $^{\mathrm{TM}}$ [2] Few authors used mathematical optimization technique to design the heat exchanger networks. This technique was first used by Takama and co workers (1980)[3] for wastewater minimization and was adopted directly for heat integration.

The synthesis of cooling water systems which takes into consideration the interaction between heat exchanger network and the cooling towers has not been fully explored.

\section{Cooling tower model}

The prediction of cooling tower thermal performance dates back to 1925 by Merkel. Several authors applied Merkel's theory to develop the cooling tower model. Bernier (1994)[4] evaluated the cooling tower thermal performance by deriving a one dimensional model based on the thermal behavior of water droplet in a spray type cooling tower. The model was able to predict the cooling tower outlet temperature and change in air humidity. The major assumptions for this model were as follows:

- Lewis factor is unity

- No packing inside the tower

The author further used Merkel's theory to predict the coefficient of performance $\left(\frac{K a V}{m_{w}}\right)$ as shown in Equation (1). This equation was derived from energy balance between the surrounding air and water droplet. The following assumptions were used:

- Water evaporation inside the tower is negligible

- The resistance surrounding water droplets is negligible

- Constant heat capacity of water 
- $\begin{gathered}\text { Transfer coefficients are independent of } \\ \text { temperature }\end{gathered}$
$\frac{K a V}{m_{w}}=c_{p w} \int_{T_{w, \text { in }}}^{T_{w, o u t}} \frac{d T_{w}}{H_{w}-H_{a}}$
Bernier (1994)[4] further used Merkel's theory to express
$\frac{K a V}{m_{w}}$ as a function of air and water flowrate as shown in

Equation (2). This implies that the effect of inlet wet bulb temperature and the inlet water temperature on the coefficient of performance is negligible.

$$
\frac{K a V}{m_{w}}=x\left[\frac{m_{w}}{m_{a}}\right]^{y}
$$

The values of $\mathrm{x}$ and $\mathrm{y}$ parameter can be determined experimentally for a given cooling tower packing. The experimental work completed by the author showed a good approximation of $\frac{K a V}{m_{w}}$. The correlation coefficient for the regression was in magnitude of 0.99 .

Kröger (2004)[5] suggested similar correlation for counter flow fills as shown below.

$$
\frac{K a_{f i}}{m_{w}}=\frac{a_{d}}{A_{f r}}\left(\frac{m_{w}}{m_{a}}\right)^{d_{d a}} A T D^{b_{d b}}
$$

where $a_{d}, d_{d a}, A T D$ and $b_{d b}$ are system parameters.

Fisenko, et al. (2004)[6] also derived a one dimensional mathematical model for a counter flow mechanical draft cooling tower by solving heat transfer, mass transfer and dynamic equations of a falling water droplet. Equation (4) was used to evaluate the cooling tower efficiency.

$$
\eta=\frac{T_{w, \text { out }}-T_{w, \text { in }}}{T_{w, \text { out }}-T_{w b}}
$$

Kim and Smith (2001)[7] also developed the cooling tower model which predicts the thermal performance a cooling tower. The authors derived a cooling tower model with the following major assumptions.

- Adiabatic operation in the cooling tower

- Water and dry air flowrate are constant

- Drift and evaporation losses neglected

- Lewis factor is constant

The performance of the cooling tower was assessed by changing the inlet conditions of water and air. The cooling tower performance was then measured by calculating the effectiveness, which is described as the ratio of actual energy transfer to maximum possible energy transfer.

Khan and Zubair (2001)[8] also developed a model which incorporates the evaporation and drift losses. Khan et al. (2004)[9] extended the work done by Khan and Zubair (2001)[8] to investigate fouling on the thermal performance of a cooling tower

Qureshi and Zubair (2006)[10] developed a cooling tower model which accounts for heat transfer in the spray zone, packing and rain zone. They further developed a fouling model to predict fouling on packing. The mass transfer coefficient was calculated from the same correlation used by Bernier (1994)[4]. Equation (5) was used to evaluate the cooling tower effectiveness. This should not be confused with the cooling tower efficiency by Fisenko et al. (2004)[6].

$$
\varepsilon=\frac{H_{a, o u t}-H_{a, \text { in }}}{H_{s, w}-H_{a, \text { in }}}
$$

The model used in this manuscript was developed by Kröger (2004)[5] by considering a control volume as shown Figure 2.

$$
\begin{array}{l|l}
m_{a}\left(1+w+\frac{d w}{d z} d z\right) \\
H_{m a}+\frac{d H_{m a}}{d z} d z
\end{array} \mid \begin{aligned}
& \left(m_{w}+\frac{d m_{w}}{d z} d z\right) \\
& T_{w}+\frac{d T_{w}}{d z} d z
\end{aligned}
$$

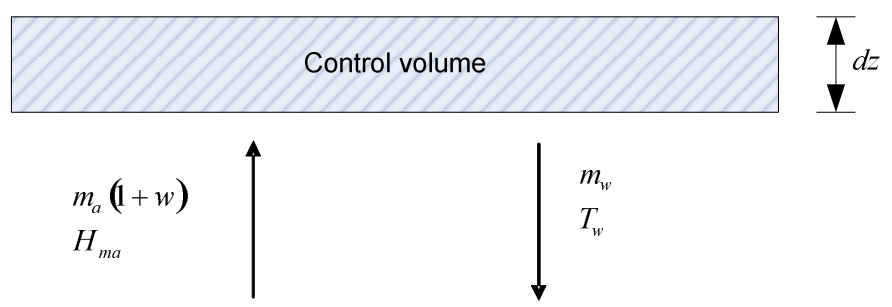

Figure 1 Control volume

The following assumptions were made:

- Interface water temperature is the same as the bulk temperature

- Air and water properties are the same at any horizontal cross section

- Heat and mass transfer area is identical

The governing equations that predict the thermal performance of a cooling tower are given by Equations (6), (7) and (8). Equation (6) and (7) define the mass and energy balance respectively for the control volume. Equation (8) defines the air enthalpy change for the control volume. 


$$
\begin{aligned}
& \frac{d m_{w}}{d z}=m_{a} \frac{d w}{d z} \\
& \frac{d T_{w}}{d z}=\frac{m_{a}}{c p_{w} m_{w}}\left(\frac{1}{c p_{w}} \frac{d H_{a}}{d z}-T_{w} \frac{d w}{d z}\right) \\
& \frac{d H_{a}}{d z}=\frac{K a_{f i} A_{f i}}{m_{a}}\left(\begin{array}{l}
L e_{f}\left(H_{a s}-H_{a}\right) \\
+\left(1-L e_{f}\right) H_{v}\left(w_{s}-w\right)
\end{array}\right)
\end{aligned}
$$

Where $a_{f i}$ is the wetted area divided by the corresponding volume of the fill and $A_{f r}$ is a frontal area. The Lewis factor, $L e_{f}$, appering in Equation (8) is the relationship between the heat-transfer coefficient and the mass-transfer coefficient, i.e. $\frac{h}{K c_{p m a}}=L e$. Lewis factor appears in many governing heat and mass transfer equations. A number of authors like Bernier (1994)[4] and Kim and Smith (2001)[7] assumed the Lewis factor to be unity. Klopper and Kröger (2005)[11] used expression given in Equation (9) to predict the value of Lewis factor. The authors studied the influence of Lewis factor on the performance prediction of wet cooling tower. Their findings were that the influence of Lewis factor diminishes when the inlet ambient air is relatively hot and humid.

$$
L e_{f}=0.866^{0.667} \frac{\left(\frac{w_{s}+0.622}{w+0.622}-1\right)}{\ln \left(\frac{w_{s}+0.622}{w+0.622}\right)}
$$

They further elaborated that increasing Lewis factor increases heat rejection, decreases water outlet temperature and decreases water evaporation rate.

This manuscript presents a technique for grassroot design of cooling water system which incorporates the performances of the cooling towers involved. The study focuses mainly on cooling systems consisting of multiple cooling towers that supply a common set of heat exchangers. The heat exchanger network is synthesized using the mathematical optimization technique. This technique is based on superstructure in which all opportunities for cooling water reuse are explored. The cooling tower model is used to predict the thermal performance of the cooling towers

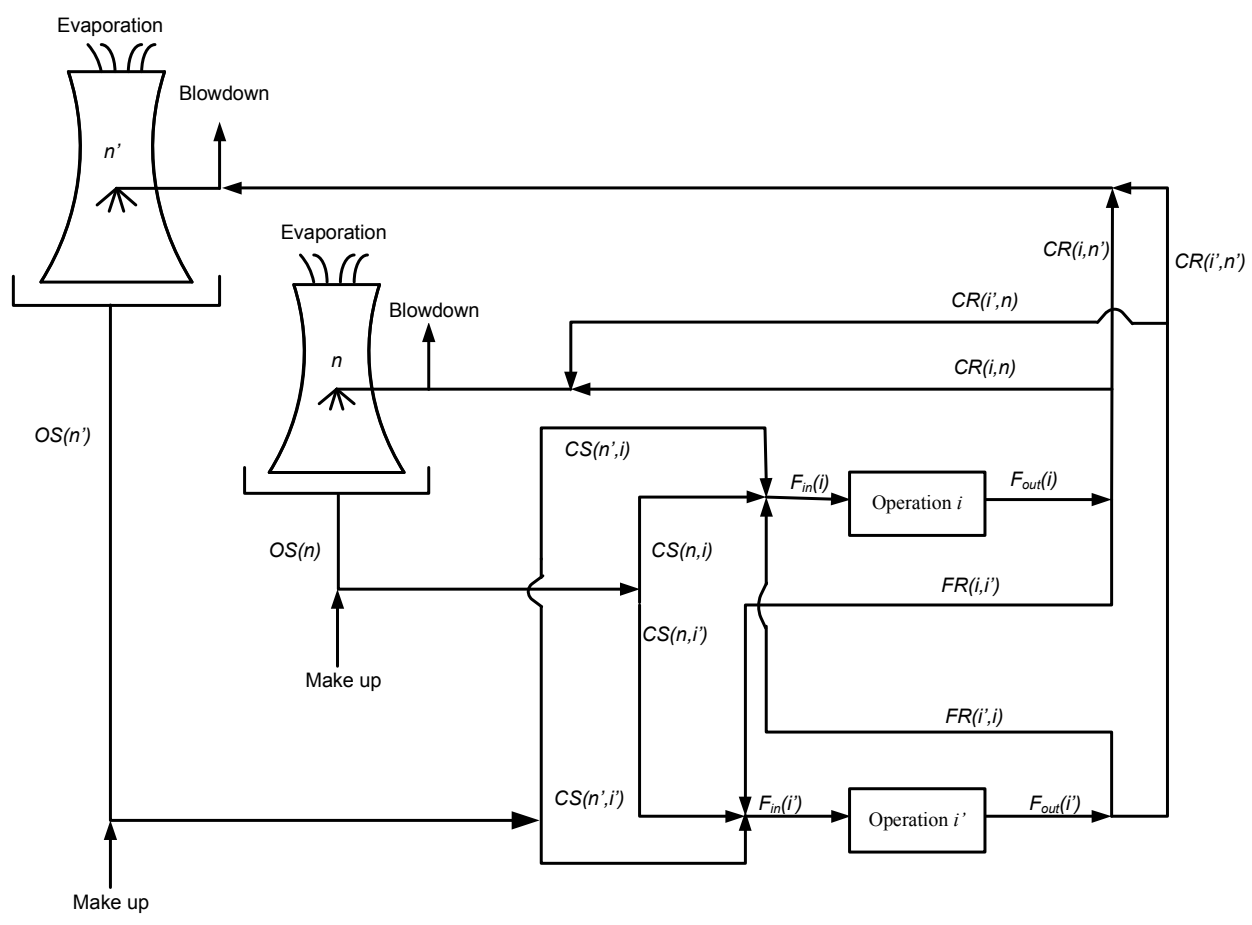

Figure 2 Superstructure for a cooling system 
The mathematical optimization formulation was developed from the superstructure given in Figure 3 by considering energy and mass balance equations across each cooling water using operation and at each node together with a cooling tower model given above (equations (5) - (9)).

\section{Conclusion}

The manuscript presents a mathematical technique for cooling water system synthesis with multiple cooling towers. This technique is more holistic because it caters for the effect of cooling tower performance on heat exchanger network. The cooling tower thermal performance is predicted using the mathematical model. The results obtained using this technique are more practical as all components of the cooling water system are embraced. Application of this technique to a case study comprising 3 cooling towers and 6 heat exchangers demonstrated that it can result in more than $17 \%$ reduction in circulating water with significant savings in associated make-up and blowdown water.

\section{References}

[1] M.M. El-halwagi, \& V. Manousiouthakis, Automatic synthesis of mass-exchanger networks with single-component targets. Chemical Engineering Science, 45(9), 1990, 2813-2831.

[2] Y.P. Wang, \& R. Smith, Wastewater minimization. Chemical Engineering Science, 49(7), 1994, 981-1006.

[3] N. Takama, T.Kuriyama, K. Shiroko, \& T. Umeda, Optimal water allocation in a petroleum refinery. Computer and Chemical Engineering, 4, 1980, 251-258.

[4] M.A. Bernier, Cooling tower performance: Theory and experiments. ASHRAE Transactions Research, 100, 1994, 114-121.

[5] D.G. Kröger, Air-cooled heat exchangers and cooling towers: mass transfer and evaporative cooling (Penn Well Corporation, USA, 2004).

[6] S.P. Fisenko, A.A. Brin, \& A.I. Petruchik, Evaporative cooling of water in a mechanical draft cooling tower. International Journal of Heat and Mass Transfer, 47, 2004, 165-177.

[7] J.K. Kim, \& R. Smith, Cooling water system design. Chemical Engineering Science, 56, 2001, 3641-3658.

[8] J.-U.-R. Khan, \& S.M. Zubair, An improved design and rating analyses of counter flow wet cooling towers. Journal of Heat Transfer ,123 (4), 2001, 770-778.
[9] J-U-R. Khan, B.A. Quereshi, \& S.M. Zubair, A comprehensive design and performance evaluation study of counter flow wet cooling towers, International Journal of Refrigeration, 27, 2004, 914-923.

[10] B.A. Qureshi, \& S.M. Zubair, A complete model of wet cooling towers with fouling in fills. Applied Thermal Engineering, 26, 2006, 1982-1989.

[11] J.C. Klopper, \& D.G. Kroger, The Lewis factor and its influence on the performance prediction of wet-cooling towers. International Journal of Thermal Science, 44, 2005, 879-884. 